\title{
Glutamate carboxypeptidase activity in human skin biopsies as a pharmacodynamic marker for clinical studies
}

\author{
Camilo Rojas ${ }^{1}$, Marigo Stathis ${ }^{1}$, Michael Polydefkis², Michelle A Rudek³ ${ }^{3}$ Ming Zhao ${ }^{3}$, Gigi J Ebenezer², \\ Barbara S Slusher ${ }^{1,2^{*}}$
}

\begin{abstract}
Background: Glutamate excitotoxicity is thought to be involved in the pathogenesis of neurodegenerative disease. One potential source of glutamate is N-acetyl-aspartyl-glutamate (NAAG) which is hydrolyzed to glutamate and $\mathrm{N}$-acetyl-aspartate (NAA) in a reaction catalyzed by glutamate carboxypeptidase (GCP). As a result, GCP inhibition is thought to be beneficial for the treatment of neurodegenerative diseases where excess glutamate is presumed pathogenic. Both pharmacological and genetic inhibition of GCP has shown therapeutic utility in preclinical models and this has led to GCP inhibitors being pursued for the treatment of nervous system disorders in human clinical trials. Specifically, GCP inhibitors are currently being developed for peripheral neuropathy and neuropathic pain. The purpose of this study was to develop a pharmacodynamic (PD) marker assay to use in clinical development. The PD marker will determine the effect of GCP inhibitors on GCP enzymatic activity in human skin as measure of inhibition in peripheral nerve and help predict drug doses required to elicit pharmacologic responses.
\end{abstract}

Methods: GCP activity was first characterized in both human skin and rat paw pads. GCP activity was then monitored in both rodent paw pads and sciatic nerve from the same animals following peripheral administration of various doses of GCP inhibitor. Significant differences among measurements were determined using two-tailed distribution, equal variance student's $t$ test.

Results: We describe for the first time, a direct and quantifiable assay to evaluate GCP enzymatic activity in human skin biopsy samples. In addition, we show that GCP activity in skin is responsive to pharmacological manipulation; GCP activity in rodent paws was inhibited in a dose response manner following peripheral administration of a potent and selective GCP inhibitor. Inhibition of GCP activity in rat paw pads was shown to correlate to inhibition of GCP activity in peripheral nerve.

Conclusion: Monitoring GCP activity in human skin after administration of GCP inhibitors could be readily used as PD marker in the clinical development of GCP inhibitors. Enzymatic activity provides a simple and direct measurement of GCP activity from tissue samples easily assessable in human subjects.

\section{Background}

Excess glutamate has been shown to be neurotoxic in many degenerative diseases of the central and peripheral nervous system [1]. One potential source of glutamate is $\mathrm{N}$-acetyl-aspartyl-glutamate (NAAG), a dipeptide found in the brain and peripheral nerves [2]. Glutamate

\footnotetext{
* Correspondence: bslusher@jhmi.edu

'Brain Science Institute, Johns Hopkins School of Medicine, 855 North Wolfe Street, Baltimore, MD 21205, USA

Full list of author information is available at the end of the article
}

carboxypeptidase (GCP) catalyzes the hydrolysis of NAAG to glutamate and N-acetyl-aspartate (NAA) [3]. There are two known GCP enzymes in the nervous system with similar pharmacological profiles: GCPII and GCPIII. GCPII, the more widely studied homolog, exhibits a high level of expression and it is found on the cell surface of astrocytes and non-myelinating Schwann cells [4-6]. GCPIII message on the other hand, is expressed in mouse cortical and cerebellar neurons in culture [7]. Inhibition of the GCP-catalyzed reaction should be

\section{Biomed Central}


beneficial for the treatment of degenerative diseases associated with excess glutamate. In fact, both genetic and pharmacological inhibition of GCP has been found to be neuroprotective in a variety of cell and animal models of disease involving excess glutamate [8-17]. Based on these data, GCP inhibitors are currently being pursued in the clinic as therapeutics for the treatment of peripheral neuropathy and neuropathic pain [18].

Clinical development of a drug can be aided by pharmacodynamic (PD) marker assays to predict drug doses required to elicit pharmacologic responses. Until recently, monitoring NAAG levels in biological matrices (e.g. CSF, plasma, and urine) was considered the PD marker of choice to monitor GCP inhibition [19]. For clinical studies, the best biological matrix to evaluate CNS/PNS penetration is cerebrospinal fluid. However, sample collection requires considerable skill and it is uncomfortable to patients. In addition, NAAG measurements involve the use of HPLC or LC-MS/MS [19] and are only a surrogate marker of enzyme inhibition. Quantifying GCP enzymatic activity on the other hand, provides a direct measurement for monitoring enzyme inhibition and is relatively straightforward to carry out. Until recently, GCP activity measurements were thought to be unfeasible as PD marker assays in the clinic because GCP was thought to be present only in nervous tissue, prostate, intestinal tract, and kidney, tissues that are not easily accessible for collection during clinical studies [20]. However, local administration of GCP inhibitors have been shown to be analgesic in peripheral pain in rats [21] and NAAG is known to be synthesized and localized in spinal sensory ganglia [22]. Further, GCP is located in Schwann cells [4,5] which exist in the epidermis [23]. Consequently, we set out to determine if GCP was measureable in human skin. In this report, we describe for the first time, quantifiable GCP activity in human skin biopsy samples. Further, to determine if GCP activity in skin is amenable to pharmacological manipulation, we conducted rodent studies on GCP activity in rat paws after dosing with GCP inhibitor. We report robust GCP activity in rodent paws which is sensitive to inhibition in a dose response manner following peripheral administration of a GCP inhibitor. Further, inhibition of GCP activity in rodent paws was shown to correlate to GCP inhibition in peripheral nerve.

\section{Methods}

\section{Human skin biopsy collection}

Punch skin biopsies $(3 \mathrm{~mm})$ were obtained from the distal thigh of healthy volunteers after anesthesia with 0.5 cc $2 \%$ lidocaine subcutaneous injection [24]. The protocol was approved by the Johns Hopkins Institutional Review Board in compliance with the Helsinki declaration. Samples were placed in cold Tris buffer ( $\mathrm{pH}$ 7.4) and GCP enzymatic activity was carried out within $1 \mathrm{~h}$ of collection.

\section{Rodent drug dosing and paw and sciatic nerve sample collection}

All experimental protocols were approved by the Institutional Animal Care and Use Committee of SoBran, Inc., Baltimore and adhered to all of the applicable institutional and governmental guidelines for the humane treatment of laboratory animals. Rats (male Wistar) were administered vehicle (HEPES saline, $\mathrm{pH}$ 7, $50 \mathrm{mM}$ ) or 2-PMPA (1, 10 and $100 \mathrm{mg} / \mathrm{kg}$, i.p.) using a dosing volume of $2 \mathrm{~mL} / \mathrm{kg}$. There were 10 animals in each group. Animals were sacrificed $1 \mathrm{~h}$ after 2-PMPA or vehicle administration. 2-PMPA brain concentrations were previously shown to be highest $50-75 \mathrm{~min}$ after i.p. administration [12]. Skin was collected from the planter hindpaw by $3 \mathrm{~mm}$ skin biopsy dissection and stored at $-80^{\circ} \mathrm{C}$ until ready for analysis. In order to obtain sciatic nerve, $1-2 \mathrm{~cm}$ incisions were made on the skin on top of the mid thigh so that sciatic nerve, gluteus superficialis muscle and biceps femoris muscle became exposed. The three were then separated and $5 \mathrm{~mm}$ of sciatic nerve was dissected out.

\section{Human skin biopsy and rodent paw and sciatic nerve sample preparation}

Human skin biopsies were sonicated in Tris buffer $(\mathrm{pH}$ 7.4, $40 \mathrm{mM}, 0.5 \mathrm{~mL}$ ) for $1 \mathrm{~min}$ in ice. The mixture was centrifuged for $2 \mathrm{~min}$ at $16000 \times \mathrm{g}$; the supernantant (containing cytosolic fraction) was removed and the resulting pellet (containing plasma membrane) was reconstituted in $70 \mu \mathrm{L}$ assay buffer (Tris $\mathrm{pH} 7.4,40 \mathrm{mM}$ containing $1 \mathrm{mM}$ $\mathrm{CoCl}_{2}$ ) and used as source of GCP in the activity assay. Rat paw pads and sciatic nerve isolated from vehicle and 2-PMPA treated animals were sonicated for $2 \mathrm{~min}$ in ice. The mixture was centrifuged for $2 \mathrm{~min}$ at $16000 \times \mathrm{g}$ and the resulting pellet was reconstituted similar to the pellets obtained from the human skin dissections.

\section{Measurement of GCP activity in human skin biopsies and rodent paw pads}

GCP activity measurements were carried out following published procedures $[3,25]$. Briefly, the reaction mixture contained $\left[{ }^{3} \mathrm{H}\right]$-NAAG $(70 \mathrm{nM}, 50 \mathrm{Ci} / \mathrm{mmol})$ and reconstituted pellet (human skin, paw pad, or sciatic nerve) in Tris- $\mathrm{HCl}$ containing $1 \mathrm{mM} \mathrm{CoCl} 2$ in a total volume of $90 \mu \mathrm{L}$. The reaction was carried out at $37^{\circ} \mathrm{C}$ at different times as indicated, and stopped with icecold sodium phosphate buffer ( $\mathrm{pH} 7.4,0.1 \mathrm{M}, 90 \mu \mathrm{L})$. When human skin was used as GCP source, the reaction was carried out in the presence and absence of the selective GCP inhibitor 2-PMPA $(1 \mu \mathrm{M})$. When rat 
tissue was used from the ex vivo study, 2-PMPA was administered i.p. and the animals were sacrificed and their paw pads removed for GCP enzymatic determinations. In both cases, blanks were obtained by incubating the reaction mixture without pellet. Duplicate aliquots of $90 \mu \mathrm{L}$ from each terminated reaction was transferred to a well in a 96-well spin column containing AG1X8 ionexchange resin; the plate was centrifuged at $1000 \mathrm{rpm}$ for 5 minutes using a Beckman GS-6R centrifuge equipped with a PTS-2000 rotor. $\left[{ }^{3} \mathrm{H}\right]$-NAAG bound to the resin and $\left[{ }^{3} \mathrm{H}\right]$-glutamate eluted in the flow through. Columns were then washed twice with formate $(1 \mathrm{M}, 90 \mu \mathrm{L})$ to ensure complete elution of $\left[{ }^{3} \mathrm{H}\right]$-glutamate. The flow through and the washes were collected in a deep 96-well block; from each well with a total volume of $270 \mu \mathrm{L}$, a $200 \mu \mathrm{L}$ aliquot was transferred to a glass scintillation vial, to which $10 \mathrm{ml}$ of Ultima-Gold (Perkin Elmer) was added. The radioactivity in each vial corresponding to $\left[{ }^{3} \mathrm{H}\right]$-glutamate was determined via a Beckman LS6000IC scintillation counter. Radioactivity values in $\mathrm{dpm}$ were converted to fmoles of glutamate using the relation $1 \mathrm{pCi} / 2.2 \mathrm{dpm}$ and the specific activity of $\left[{ }^{3} \mathrm{H}\right]$-glutamate (same as that of $\left[{ }^{3} \mathrm{H}\right]$-NAAG: 1 fmole/50 pCi). As a result, if $16711 \mathrm{dpm}\left[{ }^{3} \mathrm{H}\right]$-glutamate were measured after incubating $10 \mathrm{mg}$ tissue for $1 \mathrm{~h}$, the normalized activity would be: $16711 \mathrm{dpm} \times(1 \mathrm{pCi} / 2.2 \mathrm{dpm}) \times(1 \mathrm{fmole} / 50$ $\mathrm{pCi}) / 10 \mathrm{mg}$ tissue $=15 \mathrm{fmole} / \mathrm{h} / \mathrm{mg}$ tissue.

\section{Statistical Analysis}

Significant differences among measurements were determined using two-tailed distribution, equal variance student's t test.

\section{Determination of 2-PMPA concentration in rodent paws by LC-MS/MS}

Frozen samples were thawed in a water bath at ambient temperature and subjected to a liquid extraction using $\mathrm{MeOH}$. Samples were placed in brown glass vials containing $500 \mu \mathrm{L}$ of $100 \% \mathrm{MeOH}$. The vial was capped and mixed vigorously for $10 \mathrm{sec}$ on a vortex-mixer followed by $30 \mathrm{~min}$ on an automated multitude shaker, followed by incubation for $24 \mathrm{~h}$ at $4^{\circ} \mathrm{C}$. The top organic layer was transferred to a disposable borosilicate glass culture tube $(13 \times 100 \mathrm{~mm})$ and evaporated to dryness at $40^{\circ} \mathrm{C}$ under a gentle stream of nitrogen. The residue was reconstituted in $100 \mu \mathrm{L}$ acetonitrile-water $(1: 1, \mathrm{v} / \mathrm{v})$ containing the internal standard, temazepam $(50 \mu \mathrm{g} /$ $\mathrm{mL}$ ), by vortex mixing (30 sec) and immersion in an ultrasound bath (5 min). The sample was transferred to a $250 \mu \mathrm{L}$ polypropylene auto sampler vial sealed with a Teflon crimp cap, and a volume of $50 \mu \mathrm{L}$ was injected onto the HPLC instrument for quantitative analysis using a temperature-controlled auto sampling device operating at $10^{\circ} \mathrm{C}$.
Chromatographic analysis was performed using a Waters ACQUITY UPLC (Milford, MA, USA). Separation of the analytes from potentially interfering material was achieved at ambient temperature using a Waters Altantis column $(100 \times 2.1 \mathrm{~mm}$ i.d. $)$ packed with a $3 \mu \mathrm{m}$ ODS stationary phase, protected by a guard column packed with $3.5 \mu \mathrm{m}$ RP18 material (Milford, MA, USA). The mobile phase used for the chromatographic separation was composed of acetonitrile-water (60:40, v/ v) containing $0.1 \%$ formic acid, and was delivered isocratically at a flow rate of $0.3 \mathrm{~mL} / \mathrm{min}$. The column effluent was monitored using an AB SCIEX TRIPLE QUAD 5500 triple-quadrupole mass-spectrometric detector (Applied Biosystems, Foster City, CA, USA). The instrument was equipped with an electrospray interface, operated in a positive mode and controlled by the Analyst version 1.5 software (Applied Biosystems). The spectrometer was programmed to allow the $\left[\mathrm{MH}^{+}\right]$ion of 2-PMPA at $\mathrm{m} / \mathrm{z} 226.8$ and that of the internal standard at $\mathrm{m} / \mathrm{z} 301.1$ pass through the first quadrupole (Q1) and into the collision cell (Q2). The daughter ions for 2-PMPA $(\mathrm{m} / \mathrm{z} 191.1)$ and the internal standard $(\mathrm{m} / \mathrm{z}$ 255.1) were monitored through the third quadrupole (Q3). Calibration curves were generated over the range of 200 to $10,000 \mathrm{ng} / \mathrm{mL}$. Mouse paw pad samples were then quantitated in $\mu \mathrm{g} / \mathrm{g}$ as: nominal concentration $(\mathrm{ng} / \mathrm{mL}) \times 0.0625$ (standardized dilution $) \times$ sample weight (in $\mathrm{mg}$ ).

\section{Results and Discussion}

\section{GCP II activity is present in human skin biopsies}

Skin biopsies from human volunteers were homogenized, the homogenate was centrifuged and the pellet was used as source of GCP in the enzyme activity assay. Reconstituted pellet was then incubated with $\left[{ }^{3} \mathrm{H}\right]$ NAAG and production of glutamate was determined in the presence and absence of 2-PMPA, a highly selective GCP inhibitor (Methods) [26]. When pellets obtained from human skin biopsy were used, conversion to glutamate was $11 \pm 0.2$ fmole glutamate generated $/ \mathrm{h} / \mathrm{mg}$ tissue. GCP activity monitoring in human skin was attempted previously, but reported to exist below the limit of detection [27]. In this study, according to previous findings [27], we found that homogenate preparations of human skin exhibited a very low GCP activity that was difficult to measure. However, when using pellet preparations (methods) as source of GCP, we found significant measurable activity in human skin biopsies that was inhibited by $90 \%$ when 2-PMPA, a highly specific GCP inhibitor, was added to the assay mixture.

A time course of glutamate production after different incubation times $(0.5,1,2,3,5,7.5,14,18$ and $24 \mathrm{~h})$ was carried out. Due to the limited number of samples that can be obtained from one person at a time, samples 
from different patients were used in this study. Consequently, each time point was an independent determination; pellets were prepared from separate skin biopsies from different volunteer donors over two separate days. GCP activity was found to be linear for the first $7.5 \mathrm{~h}$ of incubation (Figure 1). $\left[{ }^{3} \mathrm{H}\right]-\mathrm{NAAG}$ at $70 \mathrm{nM}(\sim 770,000$ $\mathrm{dpm}$ ) provided robust sensitivity to follow GCP activity; there were approximately 5,000 and 80,000 dpm of $\left[{ }^{3} \mathrm{H}\right]$-glutamate after 0.5 and $7.5 \mathrm{~h}$ incubation respectively. These values corresponded to 0.6 and $10 \%$ conversion of reactant to product indicating that sufficient substrate concentration was used and that if additional GCP activity had been present, additional activity would have been observed. The linear relationship with respect to time using samples from different donors suggests that GCP levels among normal volunteers are relatively similar.

\section{GCP activity is present in rodent paw pads}

A parallel determination of GCP activity was carried out using male Wistar rat paw pads. Reconstituted pellet preparations from rat paw pads were used as source of GCP II and incubated with $\left[{ }^{3} \mathrm{H}\right]$ NAAG. The amount of GCP activity in rat paw pads was found to be $15 \pm 0.2$ fmole glutamate generated $/ \mathrm{h} / \mathrm{mg}$ tissue). Interestingly, the amount of GCP activity found in rat paw pads $(15 \pm$ $0.2 \mathrm{fmole} / \mathrm{h} / \mathrm{mg}$ tissue) was similar to that obtained from human skin (11 $\pm 0.2 \mathrm{fmole} / \mathrm{h} / \mathrm{mg}$ tissue $)$.

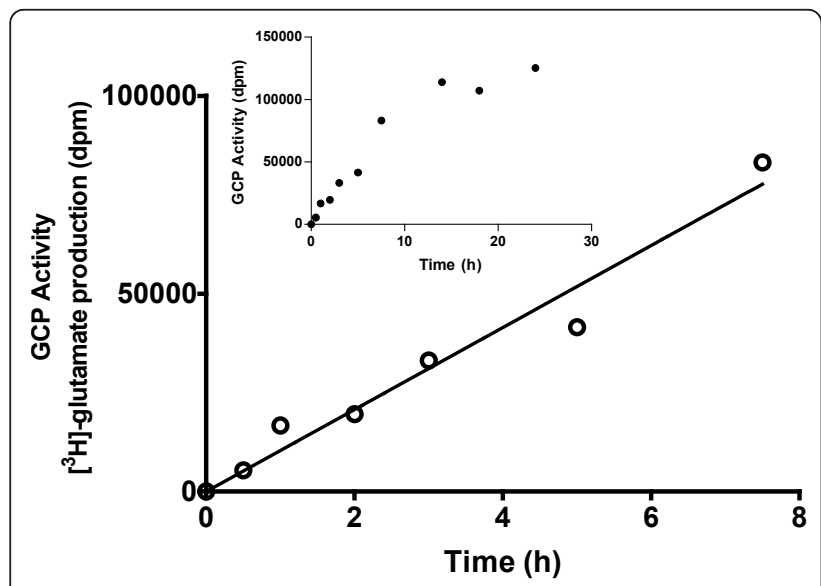

Figure 1 Dependence of GCP activity in human skin biopsy on time of incubation - Human skin biopsies were sonicated for 2 min in ice. The resulting mixture was centrifuged at $16000 \times$ g; precipitate from each preparation was used as GCP source in the activity assay. Incubations with $\left[^{3} \mathrm{H}\right]$ NAAG $(70 \mathrm{nM})$ at $37^{\circ} \mathrm{C}$ were carried out at $0.5,1,2,3,5,7.5,14,18$ and $24 \mathrm{~h}$. Time points correspond to incubations carried out with biopsies obtained from different donors. Major plot illustrates the correspondence of enzyme activity $\left(\left[{ }^{3} \mathrm{H}\right]\right.$-glutamate production in $\left.\mathrm{dpm}\right)$ with time while linearity was observed. Inset illustrates GCP activity measured at times up to $24 \mathrm{~h}$.
Peripheral administration of 2-PMPA inhibits GCP activity in rat paw pads in a dose response manner

To be useful as clinical PD marker, GCP activity in skin needs to be amenable to inhibition by peripheral administration of GCP inhibitors in a dose response manner. In order to determine if GCP activity in paw pads in vivo could be inhibited by peripheral administration of 2-PMPA, rats were treated with 1,10 and $100 \mathrm{mg} / \mathrm{kg}$ 2-PMPA (i.p.) as well as vehicle control. Animals were sacrificed $1 \mathrm{~h}$ after compound administration, paw pads isolated and GCP activity determined (Methods). GCP activity in paw pad preparations from animals treated with $1 \mathrm{mg} / \mathrm{kg} 2$-PMPA was similar to that of controls. On the other hand, paw pads from animals treated with 10 and $100 \mathrm{mg} / \mathrm{kg}$ exhibited significantly reduced GCP activity: $60 \pm 11$ and $47 \pm 11 \%$ respectively when compared to control animals (Figure 2A). Importantly, these are the doses of 2-PMPA previously shown to exhibit therapeutic benefit [13].

\section{Peripheral administration of 2-PMPA inhibits GCP activity} in sciatic nerve in a dose response manner and it correlates to inhibition observed in rat paw pads

Sciatic nerve is the target tissue for GCP inhibitors in clinical trials for peripheral neuropathy and neuropathic pain. Consequently, it is important to demonstrate that there is a correlation of GCP inhibition in skin and peripheral nerve after administration of different doses of GCP inhibitor. GCP activity in sciatic nerve preparations from animals treated with 1,10 and $100 \mathrm{mg} / \mathrm{kg} 2$-PMPA was reduced to $92 \pm 11,35 \pm 6$ and $10 \pm 4 \%$ respectively compared to activity in sciatic nerve isolated from control animals (Figure 2B). Albeit to a different extent, GCP inhibition in sciatic nerve is attained at similar 2PMPA doses (10 and $100 \mathrm{mg} / \mathrm{kg}$ i.p.) as in footpad tissue. Taken together, these results suggested that it will be possible to follow GCP inhibition in the skin as a marker of GCP inhibition in peripheral nerve.

\section{2-PMPA is measurable in rat paw pads}

Given that inhibition of GCP was observed in paw pads, we wanted to confirm the presence of 2-PMPA in paw pads after peripheral administration of 2-PMPA. Animals were given 2-PMPA (100 mg/kg, i.p.), sacrificed $1 \mathrm{~h}$ after compound administration and paw pads isolated for direct determination of 2-PMPA levels by LC-MS/MS (Methods). Since 2-PMPA detection by mass spectrometry has low sensitivity due to ion suppression, we chose to analyze samples from animals that had received $100 \mathrm{mg} / \mathrm{kg}$ 2-PMPA rather than $10 \mathrm{mg} / \mathrm{kg}$ to increase the probability of detecting 2-PMPA. The characteristic fragmentation pattern for 2-PMPA was readily detected (Figure 3A) and the chromatographic peaks of 2-PMPA and internal standard (Figure $3 \mathrm{~B}$ ) allowed for quantitation of material in the 
(A)

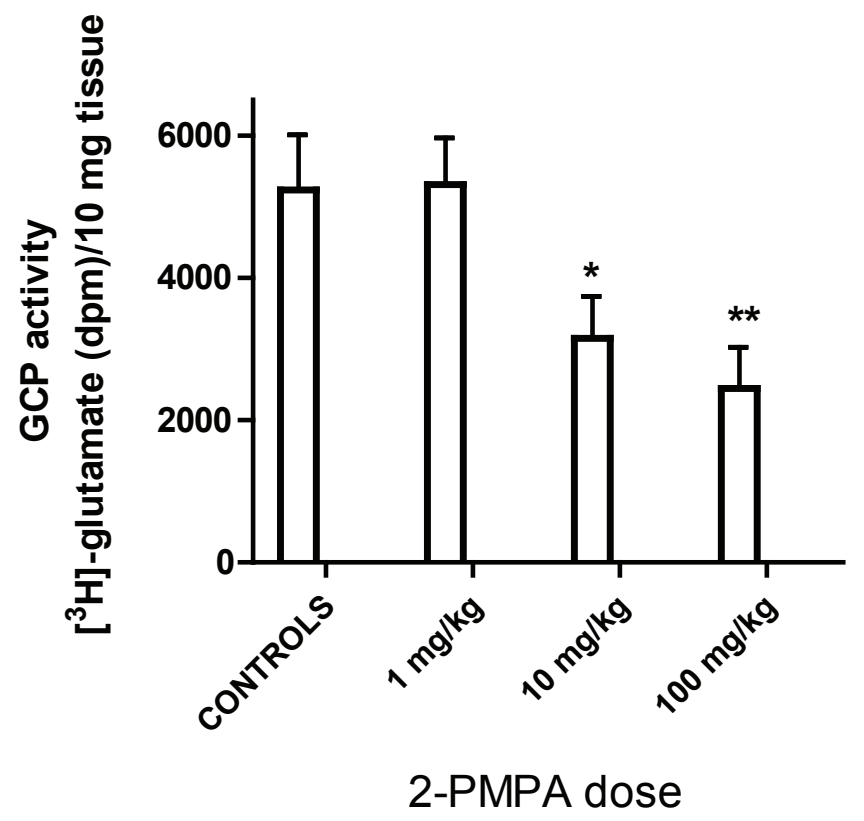

(B)

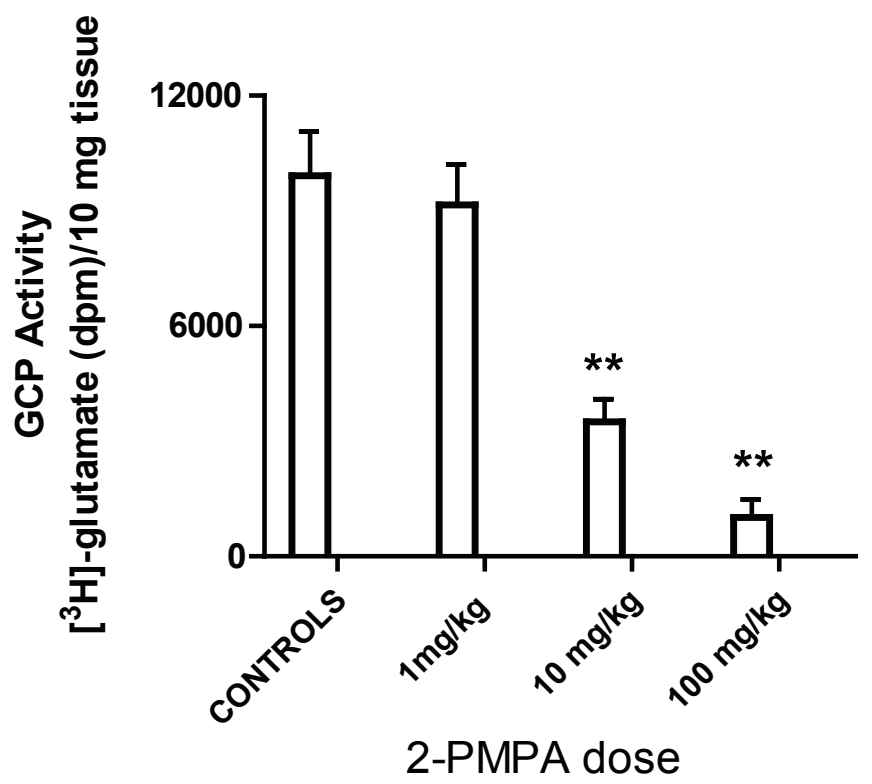

Figure 2 GCP activity in rat paw pads and sciatic nerve is inhibited by peripheral administration of 2-PMPA - Rats were treated with 2PMPA (1, 10 and $100 \mathrm{mg} / \mathrm{kg}$ i.p.) as well as vehicle control. Animals were sacrificed $1 \mathrm{~h}$ after compound administration, paw pads and sciatic nerve isolated and GCP activity determined (Methods). (A): GCP activity $\left(\left[^{3} \mathrm{H}\right]\right.$-glutamate production in dpm/10 mg tissue) in paw pads; * $\mathrm{p}<0.05$ (B): GCP activity in sciatic nerve. ${ }^{* *} \mathrm{p}<0.01$. 
(A)

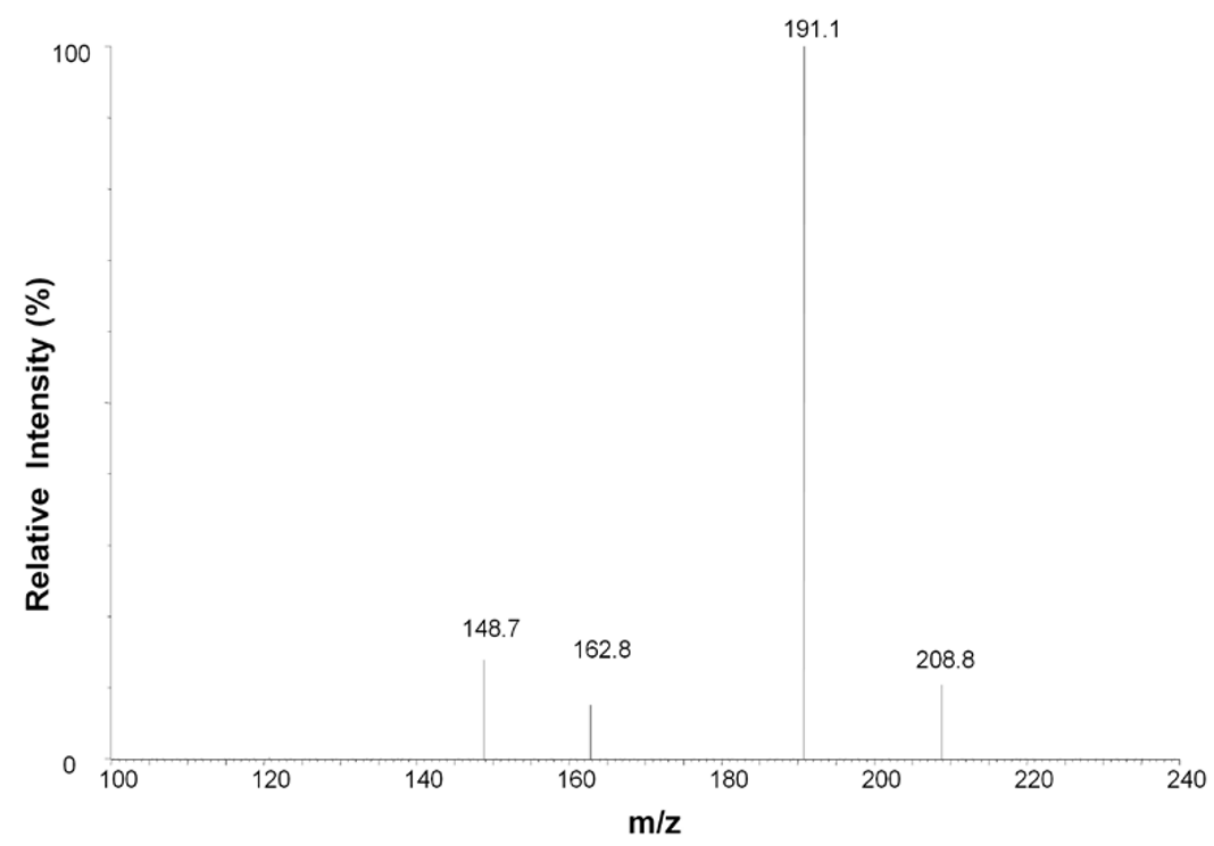

(B)
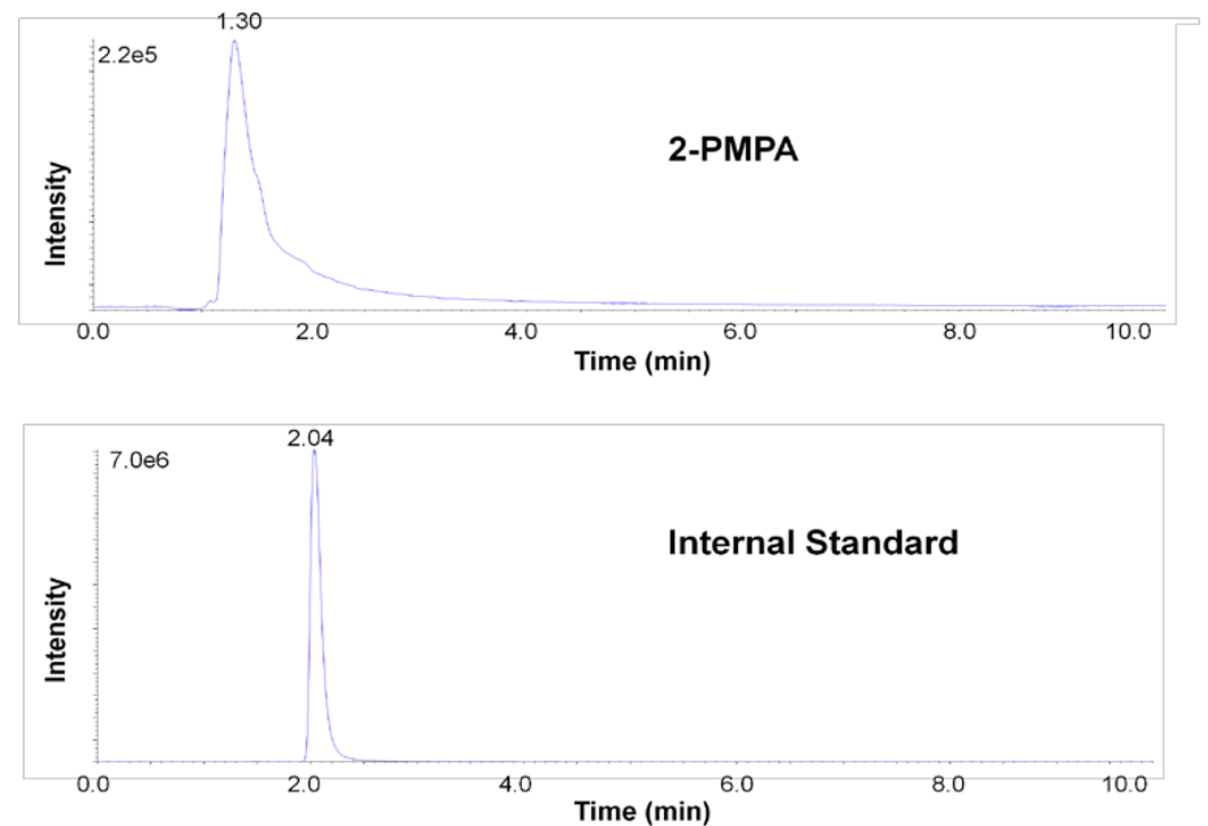

Figure 3 Measurement of 2-PMPA in rat paw pads using LC-MS/MS - (A) Daughter-scan product ion spectrum of 2-PMPA. Monitoring was carried out at $\mathrm{m} / \mathrm{z} 226.8 \rightarrow 191.1$ (B) Select rodent paw pad obtained 1 hour after 2-PMPA (100 mg/kg, i.p.) administration. Retention times for 2-PMPA and internal standard (temazepan) were approximately 1.3 and 2.0 min respectively. When rodent paw pads from untreated animals were used, only the internal standard peak was observed. 
sample. Paw pads from animals that were treated with compound showed $38 \pm 5 \mu \mathrm{g} / \mathrm{g}$ tissue $(\mathrm{n}=9)$ (Figure $3 \mathrm{~B})$ a concentration high enough to inhibit GCP activity [25] while the compound was undetectable in paw pads isolated from vehicle-treated animals.

\section{Conclusions}

As a biomarker of GCP inhibition in the clinic, skin biopsy measurements of GCP activity has three areas of improvement over the prior NAAG bioassay including simpler sample collections, less expensive and time consuming sample analyses, and the ability to quantitate direct vs. indirect measurement of GCP activity. Sample collection for NAAG bioanalysis involves CSF collection which requires considerable skill and can be uncomfortable to patients; the newly described procedure uses skin biopsies which is readily accessible and can be collected multiple times from a single subject permitting the ability to evaluate GCP activity before and after administration of the drug. NAAG analysis uses mass spectrometry which requires a specialized laboratory and expensive instrumentation. The new procedure monitors GCP activity in the skin ex vivo by following the conversion of $\left[{ }^{3} \mathrm{H}\right]$-NAAG to $\left[{ }^{3} \mathrm{H}\right]$ glutamate in a simple enzymatic assay that can be carried out in a standard biochemistry laboratory. Finally, the older procedure involved measurements of NAAG levels as surrogate markers of GCP activity; the new procedure monitors GCP enzymatic activity directly. In short, monitoring of GCP activity in human skin after administration of GCP inhibitors can be readily utilized as a PD marker in the clinical development of GCP inhibitors. The activity assay provides a simple and direct measurement of GCP activity from tissue samples easily assessable in human subjects.

\section{Abbreviations}

GCP: glutamate carboxypeptidase; NAAG: N-acetyl-aspartyl-glutamate; NAA: $\mathrm{N}$-acetyl-aspartate; CSF: cerebrospinal fluid; CNS: central nervous system; PNS: peripheral nervous system; HPLC: High Pressure Liquid Chromatography; LCMS/MS: liquid chromatography-tandem mass spectrometry; PD: pharmacodynamic; 2-PMPA: 2-(phosphonomethyl) pentanedioic acid.

\section{Acknowledgements and Funding}

This work was supported in part by the Analytical Pharmacology Core of the Sidney Kimmel Comprehensive Cancer Center at Johns Hopkins ( $\mathrm{NIH}$ grants UL1 RR025005; MAR and MZ), the Shared Instrument Grant (1S10RR02682401; MAR), and the Juvenile Diabetes Research Foundation (MP, RO, and GE).

\section{Author details}

'Brain Science Institute, Johns Hopkins School of Medicine, 855 North Wolfe Street, Baltimore, MD 21205, USA. ²Department of Neurology, Johns Hopkins School of Medicine, 1550 Orleans Street, Baltimore, MD 21231, USA.

${ }^{3}$ Department of Oncology, Johns Hopkins School of Medicine, 1650 Orleans Street, Baltimore, MD 21231, USA.

\section{Authors' contributions}

CR helped with study design and writing of the manuscript. MS carried out GCP activity measurements in the different biological matrices. MP and GJE organized the collection of human skin. MAR and MZ carried out 2-PMPA analysis by LC-MS/MS. BSS conceived the study and study design and guided the writing and editing of the manuscript. All authors read and approved the final manuscript.

\section{Competing interests}

CR, MS and BSS are former Eisai employees; Eisai is currently working on the development of a GCP inhibitor.

Received: 27 October 2010 Accepted: 9 March 2011

Published: 9 March 2011

\section{References}

1. Doble A: The role of excitotoxicity in neurodegenerative disease: implications for therapy. Pharmacol Ther 1999, 81:163-221.

2. Neale JH, Olszewski RT, Gehl LM, Wroblewska B, Bzdega T: The neurotransmitter $\mathrm{N}$-acetylaspartylglutamate in models of pain, ALS, diabetic neuropathy, CNS injury and schizophrenia. Trends Pharmacol Sci 2005, 26:477-484.

3. Robinson MB, Blakely RD, Couto R, Coyle JT: Hydrolysis of the brain dipeptide $\mathrm{N}$-acetyl-L-aspartyl-L-glutamate. Identification and characterization of a novel $\mathrm{N}$-acetylated alpha-linked acidic dipeptidase activity from rat brain. J Biol Chem 1987, 262:14498-14506.

4. Berger UV, Carter RE, McKee M, Coyle JT: N-acetylated alpha-linked acidic dipeptidase is expressed by non-myelinating Schwann cells in the peripheral nervous system. J Neurocytol 1995, 24:99-109.

5. Carozzi VA, Canta A, Oggioni N, Ceresa C, Marmiroli P, Konvalinka J, Zoia C, Bossi M, Ferrarese C, Tredici G, Cavaletti G: Expression and distribution of 'high affinity' glutamate transporters GLT1, GLAST, EAAC1 and of GCPII in the rat peripheral nervous system. J Anat 2008, 213:539-546.

6. Cassidy $\mathrm{M}$, Neale $\mathrm{JH}$ : $\mathrm{N}$-acetylaspartylglutamate catabolism is achieved by an enzyme on the cell surface of neurons and glia. Neuropeptides 1993, 24:271-278.

7. Bzdega T, Crowe SL, Ramadan ER, Sciarretta KH, Olszewski RT, Ojeifo OA, Rafalski VA, Wroblewska B, Neale JH: The cloning and characterization of a second brain enzyme with NAAG peptidase activity. I Neurochem 2004, 89:627-635.

8. Bacich DJ, Wozniak KM, Lu XC, O'Keefe DS, Callizot N, Heston WD, Slusher BS: Mice lacking glutamate carboxypeptidase II are protected from peripheral neuropathy and ischemic brain injury. J Neurochem 2005, 95:314-323.

9. Carozzi VA, Chiorazzi A, Canta A, Lapidus RG, Slusher BS, Wozniak KM, Cavaletti G: Glutamate carboxypeptidase inhibition reduces the severity of chemotherapy-induced peripheral neurotoxicity in rat. Neurotox Res 2009, 17:380-391.

10. Chen SR, Wozniak KM, Slusher BS, Pan HL: Effect of 2-(phosphono-methyl)pentanedioic acid on allodynia and afferent ectopic discharges in a rat model of neuropathic pain. J Pharmacol Exp Ther 2002, 300:662-667.

11. Ghadge GD, Slusher BS, Bodner A, Canto MD, Wozniak K, Thomas AG, Rojas C, Tsukamoto T, Majer P, Miller RJ, Monti AL, Roos RP: Glutamate carboxypeptidase II inhibition protects motor neurons from death in familial amyotrophic lateral sclerosis models. Proc Natl Acad Sci USA 2003, 100:9554-9559.

12. Nagel J, Belozertseva I, Greco S, Kashkin V, Malyshkin A, Jirgensons A, Shekunova E, Eilbacher B, Bespalov A, Danysz W: Effects of NAAG peptidase inhibitor 2-PMPA in model chronic pain - relation to brain concentration. Neuropharmacology 2006, 51:1163-1171.

13. Slusher BS, Vornov JJ, Thomas AG, Hurn PD, Harukuni I, Bhardwaj A, Traystman RJ, Robinson MB, Britton P, Lu XC, Tortella FC, Wozniak KM, Yudkoff M, Potter BM, Jackson PF: Selective inhibition of NAALADase, which converts NAAG to glutamate, reduces ischemic brain injury. Nat Med 1999, 5:1396-1402.

14. Xi ZX, Li X, Peng XQ, Li J, Chun L, Gardner EL, Thomas AG, Slusher BS, Ashby CR Jr: Inhibition of NAALADase by 2-PMPA attenuates cocaineinduced relapse in rats: a NAAG-mGluR2/3-mediated mechanism. J Neurochem 2010, 112:564-576.

15. Zhang W, Murakawa Y, Wozniak KM, Slusher B, Sima AA: The preventive and therapeutic effects of GCPII (NAALADase) inhibition on painful and sensory diabetic neuropathy. J Neurol Sci 2006, 247:217-223.

16. Zhang W, Slusher B, Murakawa Y, Wozniak KM, Tsukamoto T, Jackson PF, Sima AA: GCPII (NAALADase) inhibition prevents long-term diabetic neuropathy in type 1 diabetic BB/Wor rats. J Neurol Sci 2002, 194:21-28. 
17. Zhou J, Neale JH, Pomper MG, Kozikowski AP: NAAG peptidase inhibitors and their potential for diagnosis and therapy. Nat Rev Drug Discov 2005, 4:1015-1026.

18. van der Post JP, de Visser SJ, de Kam ML, Woelfler M, Hilt DC, Vornov J, Burak ES, Bortey E, Slusher BS, Limsakun T, Cohen AF, VanGerven JM: The central nervous system effects, pharmacokinetics and safety of the NAALADase-inhibitor GPI 5693. Br J Clin Pharmacol 2005, 60:128-136.

19. Thomas AG, Rojas CJ, Hill JR, Shaw M, Slusher BS: Bioanalysis of NAAG as a Marker of GCP II Inhibition. Anal Biochem 2010, 404:94-96.

20. Slusher BS, Robinson MB, Tsai G, Simmons ML, Richards SS, Coyle JT: Rat brain $\mathrm{N}$-acetylated alpha-linked acidic dipeptidase activity. Purification and immunologic characterization. J Biol Chem 1990, 265:21297-21301.

21. Yamamoto T, Saito O, Aoe T, Bartolozzi A, Sarva J, Zhou J, Kozikowski A, Wroblewska B, Bzdega T, Neale JH: Local administration of $\mathrm{N}$ acetylaspartylglutamate (NAAG) peptidase inhibitors is analgesic in peripheral pain in rats. Eur J Neurosci 2007, 25:147-158.

22. Cangro CB, Namboodiri MA, Sklar LA, Corigliano-Murphy A, Neale JH: Immunohistochemistry and biosynthesis of $\mathrm{N}$-acetylaspartylglutamate in spinal sensory ganglia. J Neurochem 1987, 49:1579-1588.

23. Ebenezer GJ, McArthur JC, Thomas D, Murinson B, Hauer P, Polydefkis M, Griffin JW: Denervation of skin in neuropathies: the sequence of axonal and Schwann cell changes in skin biopsies. Brain 2007, 130:2703-2714.

24. Griffin JW, McArthur JC, Polydefkis M: Assessment of cutaneous innervation by skin biopsies. Curr Opin Neurol 2001, 14:655-659.

25. Rojas C, Frazier ST, Flanary J, Slusher BS: Kinetics and inhibition of glutamate carboxypeptidase II using a microplate assay. Anal Biochem 2002, 310:50-54.

26. Jackson PF, Slusher BS: Design of NAALADase inhibitors: a novel neuroprotective strategy. Curr Med Chem 2001, 8:949-957.

27. Rovenska M, Hlouchova K, Sacha P, Mlcochova P, Horak V, Zamecnik J, Barinka C, Konvalinka J: Tissue expression and enzymologic characterization of human prostate specific membrane antigen and its rat and pig orthologs. Prostate 2008, 68:171-182.

doi:10.1186/1479-5876-9-27

Cite this article as: Rojas et al:: Glutamate carboxypeptidase activity in human skin biopsies as a pharmacodynamic marker for clinical studies. Journal of Translational Medicine 2011 9:27.

\section{Submit your next manuscript to BioMed Central and take full advantage of:}

- Convenient online submission

- Thorough peer review

- No space constraints or color figure charges

- Immediate publication on acceptance

- Inclusion in PubMed, CAS, Scopus and Google Scholar

- Research which is freely available for redistribution

Submit your manuscript at www.biomedcentral.com/submit
Biomed Central 